\title{
Multilayer GaAs-Based Heterostructures with Holographic Concentrator for Solar Cells
}

\author{
Azamatov Zakirdjan Tahirovich ${ }^{1}$, Akbarova Nigora Alimdjanovna ${ }^{1}$, \\ Mavlyanov Abdulaziz Shavkatovich ${ }^{2}$, Muminov Ramizulla Abdullayevich ${ }^{3 *}$, \\ Redkorechev Vecheslav Ivanovich1, Tukfatullin Oskar Faritovich ${ }^{3}$, \\ Khusainov Ilhom Aminovich 1 \\ ${ }^{1}$ The Institute of Ion-Plasma and Laser Technologies, The Academy of Sciences of the Republic of Uzbekistan, \\ Tashkent, Uzbekistan \\ ${ }^{2}$ Department of Electronics and Microelectronics, Tashkent State Technical University, Tashkent, Uzbekistan \\ ${ }^{3}$ Physics Technical Institute "Physics-Sun", The Academy of Sciences of the Republic of Uzbekistan, Tashkent, \\ Uzbekistan \\ Email: ${ }^{*}$ bahazeb@yandex.ru
}

Received 28 June 2014; revised 17 August 2014; accepted 12 September 2014

Copyright (C) 2014 by authors and Scientific Research Publishing Inc.

This work is licensed under the Creative Commons Attribution International License (CC BY). http://creativecommons.org/licenses/by/4.0/

(c) (i) Open Access

\begin{abstract}
The present paper studies the issue of forming a diffraction concentrator in the form of relief diffraction gratings. The possibility of their application for solar energy systems based on GaAs heterostructures has been studied. It was shown that the use of diffractive and holographic concentrators proves to be very effective, since they provide for the increased radiant flux onto sensitive surface of the solar cell, whereas no automatic solar tracker is required. This will create novel approaches for a wide range application of gallium arsenide solar cells.
\end{abstract}

\section{Keywords}

Holographic Concentrator, Diffraction Gratings, GaAs Heterostructures

\section{Introduction}

It is widely known, that solar cells are currently well developed on the basis of polycrystalline and single-crystal silicon. The highest possible efficiency ratio in laboratory samples is approximately $25 \%-26 \%$, and in com-

"Corresponding author.

How to cite this paper: Tahirovich, A.Z., Alimdjanovna, A.N., Shavkatovich, M.A., Abdullayevich, M.R., Ivanovich, R.V., Faritovich, T.O. and Aminovich, K.I. (2014) Multilayer GaAs-Based Heterostructures with Holographic Concentrator for Solar Cells. Materials Sciences and Applications, 5, 871-875. http://dx.doi.org/10.4236/msa.2014.512088 
mercially available solar cells developed on single crystals it reaches $20 \%-22 \%$ and $16 \%-18 \%$ for polycrystalline. The dimensions of the sensitive surface are $156 \times 156 \mathrm{~mm}$ and the thickness is about 200 microns. The share of silicon solar cells in the mass production is about $90 \%$, whereas the share of thin-film solar cells in the world market is about $10 \%$. Moreover, we are witnessing over the past few years certain achievements in the development of solar cells based on the cadmium telluride with an efficiency ratio of $20.4 \%$ for single trial samples, and $21.2 \%$ for solar cells based on thin-film cells of copper selenide-indium-gallium. Record efficiency was reported for the cascade solar cells based on compounds $\mathrm{A}^{\mathrm{III}} \mathrm{B}^{\mathrm{IV}}$, with $\sim 44 \%$ efficiency ratio for the concentrated-solar-radiation types and 38.8\% ratio for conventional types. However, in spite of these recent achievements in the development of solar cells it becomes necessary to compete with conventional energy based on hydrocarbons. This goal becomes achievable if we take into account the fact that $1 \mathrm{~kW} \cdot \mathrm{h}$ of electricity generated by solar panels cost in 2008 approximately \$US 0.35. Nowadays, this figure is already averages $\$$ US $0.11-0.12$. The aim is to reduce the cost of $1 \mathrm{~kW} \cdot \mathrm{h}$ to $\$ 0.08-0.09$. In view of the above mentioned, the problem continues to be associated with the need to develop new designs and technologies to build solar cell structures effectively operating on the basis of novel scientific approaches, ideas and mechanisms. Therefore, the worldwide scientific community is in a constant search for new physical, technical and technological techniques, which could let obtain high efficiency solar cells. One solution to this problem is the development of novel physical foundations improving the efficiency of direct conversion of solar radiation into electrical energy using the recent achievements of modern nanotechnology (Nanophysics), holographic coatings, superlattices, functional ceramic layers, zero-dimensional inclusions. This will certainly contribute to the formation of novel technical, technological and design solutions for a new generation of solar cells.

In order to obtain high-performance, high-current semiconductor solar cells that directly convert solar radiation to electricity, it is necessary to develop the sandwich structures with varying band gap. Such multilayer (cascade) solar cells are currently being widely developed utilizing heterostructures based on Gallium Arsenide Aluminum Gallium Arsenide [1].

Gallium Arsenide heterostructure solar cells represent structures containing several epitaxial layers of GaInP, GaInAs or AlGaInP grown on a substrate of a single Germanium crystal. Implementation of such type of multicascade solar cells serves as a basis for generation of electron-hole pairs due to the absorption of wide spectral range of solar radiation. Such multi-cascade elements manifest stunning efficiency ratios ( 40\%) [2]. In order to ensure high efficiency of conversion of solar radiation to electricity from the unit area of the heterostructure, optical light concentrators or flat Fresnel lens are commonly used. The ratio of the area size of the cell and the one of the concentrator, determines the multiplicity of light concentration. For maximum efficiency of concentrator, it is necessary to constantly use the automatic Sun tracking rotary device that constantly directs the flux of solar radiation toward the sensitive surface of the solar cell. Figure 1 shows the configuration of a holographic concentrator for silicon solar cells and no solar tracker is needed. The concentration of the light in this case is not so high compared to systems with embedded concentrating mirrors, prisms or lenses. However, in contrast to these traditional types of concentrators, diffraction and holographic concentrators are incidentally characterized by relative advantages. Moreover, no separate solar tracking system is required and they rather ensure daily automatic solar tracking embedded. Consequently, the daily amount of electrical energy generated increases approximately by one third [3].

Hybrid holographic solar concentrator has the following design. Rectangular planes of holographic film

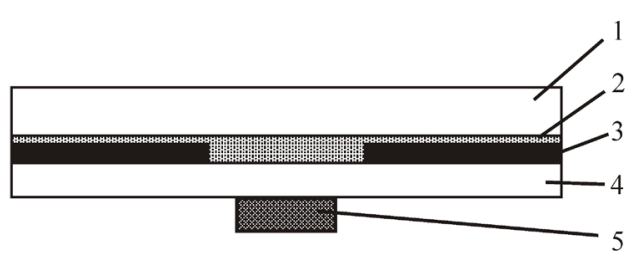

(a)

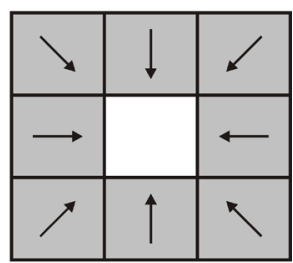

(b)

Figure 1. Design configuration of the hybrid holographic concentrator. (a) Hybrid concentrator; (b) Layout diagram of the holographic film between the substrates, the arrows indicate the priority direction of light reflection from the film. 1, 4-glass plates. 2-immersion filling with organic dye. 3-a holographic film. 5-solar cell. 
(Figure 1(b)) (cut in such manner as to reflect light predominantly in the direction of the arrows) are superimposed on the glass substrate 4 (Figure 1). Shortly thereafter, solution of an organic dye performing the same immersion role is on the surface of the film. The second glass plate 1 serving as the fiber is superimposed on top of the structure.

Hybrid holographic solar concentrator operates in the following manner. Solar radiation of various wavelengths runs through the upper plate 1 and then the layer 2 of the dye in the immersion liquid. Dye partially re-emits shorter wavelengths into the spectral region of absorption of the solar cells. When sunlight falls on the holographic grating, decomposed spectrum appears as a result of Bragg diffraction [3]:

$$
2 d \sin \theta=\lambda_{1}
$$

( $d$ - the period of the holographic grating, $\theta$-angle of diffraction)

Holographic grating parameters are chosen so as to meet the following two requirements. Firstly, the light with a wavelength $\lambda_{1}$ equals the intrinsic absorption band of the material of the solar cell 5. Secondly, holographic gratings are oriented in such a manner that the angle of reflection (diffraction) of light with a wavelength $\lambda_{1}$ for plate 1 be the total internal reflection angle. This leads to the event that radiation of this wavelength is reflected from the substrate-air interface and hits back the holographic grating, thus the process is repeated multiple times until the radiation is released through the central region free of holographic grating, passes through the second transparent plate 4 and falls onto solar cell 5 .

\section{Methods of Investigation and Discussion of the Experimental Results}

A holographic planar concentrator [4] consisting of a transparent plate and reflective holographic element, wherein the transparent plate serves as light-guide for diffracted radiation from the holographic element. The radiation reflected from the boundary between two media (air-transparent plate) runs through the gap between the gratings constituting the holographic element and hits the sensitive surface of a solar cell. Holographic planar concentrator described in reference [3], collects the entire spectrum of solar radiation in the spectral range 350 to $1400 \mu \mathrm{m}$.

The device described by V. A. Pilipovich [5] is characterized by greater efficiency and represents the holographic planar concentrator comprising of a transparent flat plate and holographic element adjacent to its entrance face formed by two adjacent holographic gratings diffraction angles of which have opposite signs. Such design allows boosting the level of concentration of incident solar radiation along single coordinate due to multiple total internal reflection of solar radiation in the light guide plate. Additional efficiency of use of sunlight can be achieved by using dyes re-emitting. Using dyes re-emitting in converters of solar energy was first proposed by Bezrodniy B. I., Dobro L. F., Ishenko A. A. [6] and Derevanko N. A., Dobro L. F., Ishenko A. A., Muravyova T. M. [7].

The present paper describes the possibility of implementation of diffraction, holographic and spectral concentrators for solar concentration on solar cell based on GaAs heterostructures.

We have studied characteristics and properties of diffraction concentrators in the form of relief diffraction gratings with a frequency of bars of $40 \mathrm{~mm}-1$ made out of polyvinyl rectangular plates of $0.2 \mathrm{~mm}$ thickness with an area of $10 \times 10 \mathrm{~mm}$ with bars of parallel faces. The plate was placed at a distance of $10 \mathrm{~mm}$ from the surface of cell and illuminated by remote light source. When illuminated, a strip with width of $10 \mathrm{~mm}$ of increased brightness appears beyond the area of shadow perpendicular to the plate. Measurements showed that the lighting (flux) in the area of increased brightness increases twofold and three-fold compared to normal brightness of the illuminated area. Thereafter, we measured the angles of illumination where the lighting in the area of increased brightness remains increased by 2 times. Measurements showed that the angle of lighting in the plane parallel to the grating grooves can vary in the range $\pm 40^{\circ}$, whereas in the plane perpendicular to the grating plane in the range $\pm 30^{\circ}$.

Based on these results we have trial tested the diffraction concentrator (Figure 2).

Illumination of solar cell does not change when lighting angles are $\pm 40^{\circ}$. The main advantage of the diffraction concentrator is ease of manufacture and low cost.

A holographic concentrator is also based on the use of reflective diffraction micro gratings obtained by holographic technique and embossed on polistrol film with reflective coating. Geometry of the micro gratings is calculated based on the main task of the holographic concentrator, i.e. to collect maximum solar radiation coming at different angles on GaAs solar cell panel (at daily movement of the sun). Based on the calculated geometry of 
2

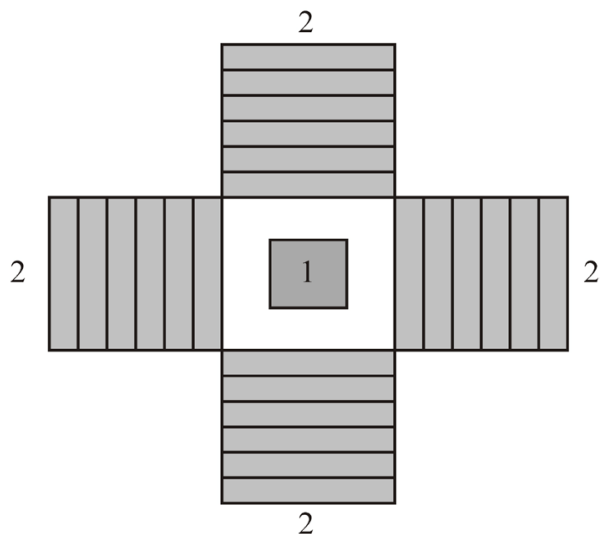

Figure 2. Diffraction concentrator. 1-solar cell. 2-gratings on polystyrene.

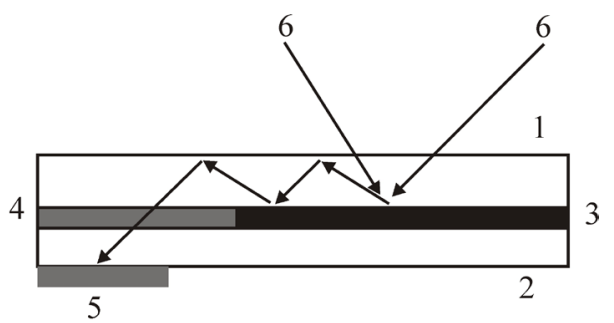

Figure 3. Prototype of the element of the holographic concentrator. 1, 2-glass plate, 3holographic film, 4-immersion liquid, 5light detector, 6-sunlight.

location of micro gratings and in accordance with technology of production of rainbow holograms [8], a holographic film was produced which in conjunction with respective glass plate accordingly represents prototype of the element of the holographic concentrator (Figure 3).

Between glass plates 1 and 2 the immersion liquid 4 and holographic film 3 are inserted. Upon illumination of the cell by incident light 6 falling at different angles, variation of illumination on the light detector 5 was measured. Changing illumination angle within the range $\pm 45^{\circ}$ the illumination was steady increased 4 to 5 times.

Based on the results of trials we have been able to design hybrid solar concentrator [9] for increase of efficiency of utilization of incident solar radiation and boosting the ratio of conversion of radiation into electric energy.

\section{Conclusions}

Utilization of diffraction and holographic concentrators in the structure thus can increase the efficiency of use of solar radiation due to several factors:

- absence of the Sun tracking system;

- increased use of solar radiation while the total area of solar cell remains unchanged due to implementation of the organic dye for converting the short-wave part of the spectrum of solar radiation into radiation with a wavelength falling within the absorption band of the solar cell;

- reduced cost of solar panels due to reduced size of gallium arsenide solar cells.

All these serve as the basis for a wide scale application of gallium-arsenide solar cells.

\section{References}

[1] Yamaguchi, M., Nishimura, K.-I., Sasaki, T., Suzuki, H., et al. (2008) Novel Materials for High-Efficiency III-V MultiJunction Solar Cells. Solar Energy, 82, 173-180.

[2] Yamaguchi, M., Takamoto, T., Araki, K. and Ekins-Daukes, N. (2005) Multi-Junction III-V Solar Cells: Current Status 
and Future Potential. Solar Energy, 79, 78-85.

[3] Professor Eduardo Gahvan, Solar Energy Technology Trends and Opportunities. Materials of the 6th Meeting of the Asia Solar Energy Forum, Tashkent, 20-23 November 2013, p. 39

[4] Rosenberg, G.A. (1999) Device for Concentrating Optical Radiation, US Patent 6274860.

[5] Pilipovich, V.A., et al. (2010) Holographic Solar Concentrator. Patent of the Russian Federation, No. 2403510.

[6] Bezrodniy, B.I., Dobro, L.F. and Ishenko, A.A. (2001) Dye Laser Based on the Polyurethane Matrix. Technical Physics Journal, 71, 72-78.

[7] Derevanko, N.A., Dobro, L.F., Ishenko, A.A. and Muravyova, T.M. (1991) Polymethine Dye as Luminescent Solar Concentrators. In: New Materials for Solar Energy, VNII of Monocrystals, Kharkiv, 23-32.

[8] Galperin, A.D. and Samayev, V.P. (1988) Methods of Recording and Reproduction of Fine Relief-Phase Holograms. Opto-Mechanical Industry, No. 11, 49-57.

[9] Azamatov, Z.T., Akbarova, N.A., Redkorechev, V.I. and Khusainov, I.A. (2014) Hybrid Holographic Concentrator of Solar Energy. Application for a Patent, FAP No. 20130092. 
Scientific Research Publishing (SCIRP) is one of the largest Open Access journal publishers. It is currently publishing more than 200 open access, online, peer-reviewed journals covering a wide range of academic disciplines. SCIRP serves the worldwide academic communities and contributes to the progress and application of science with its publication.

Other selected journals from SCIRP are listed as below. Submit your manuscript to us via either submit@scirp.org or Online Submission Portal.
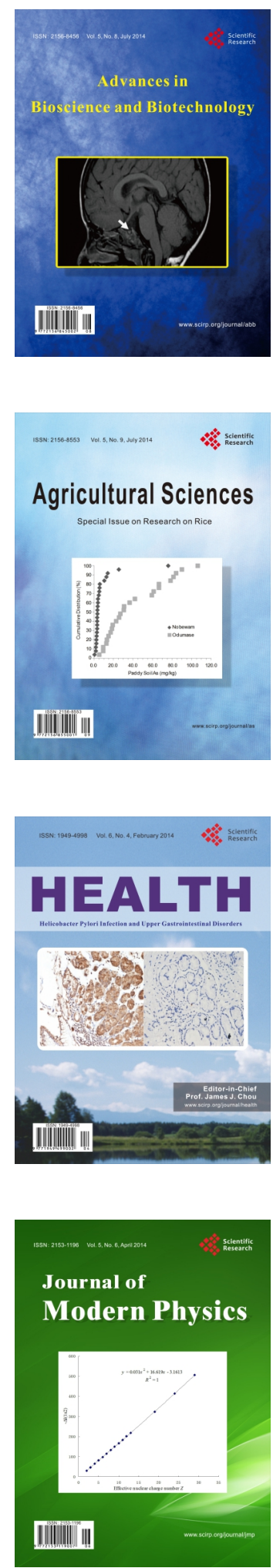
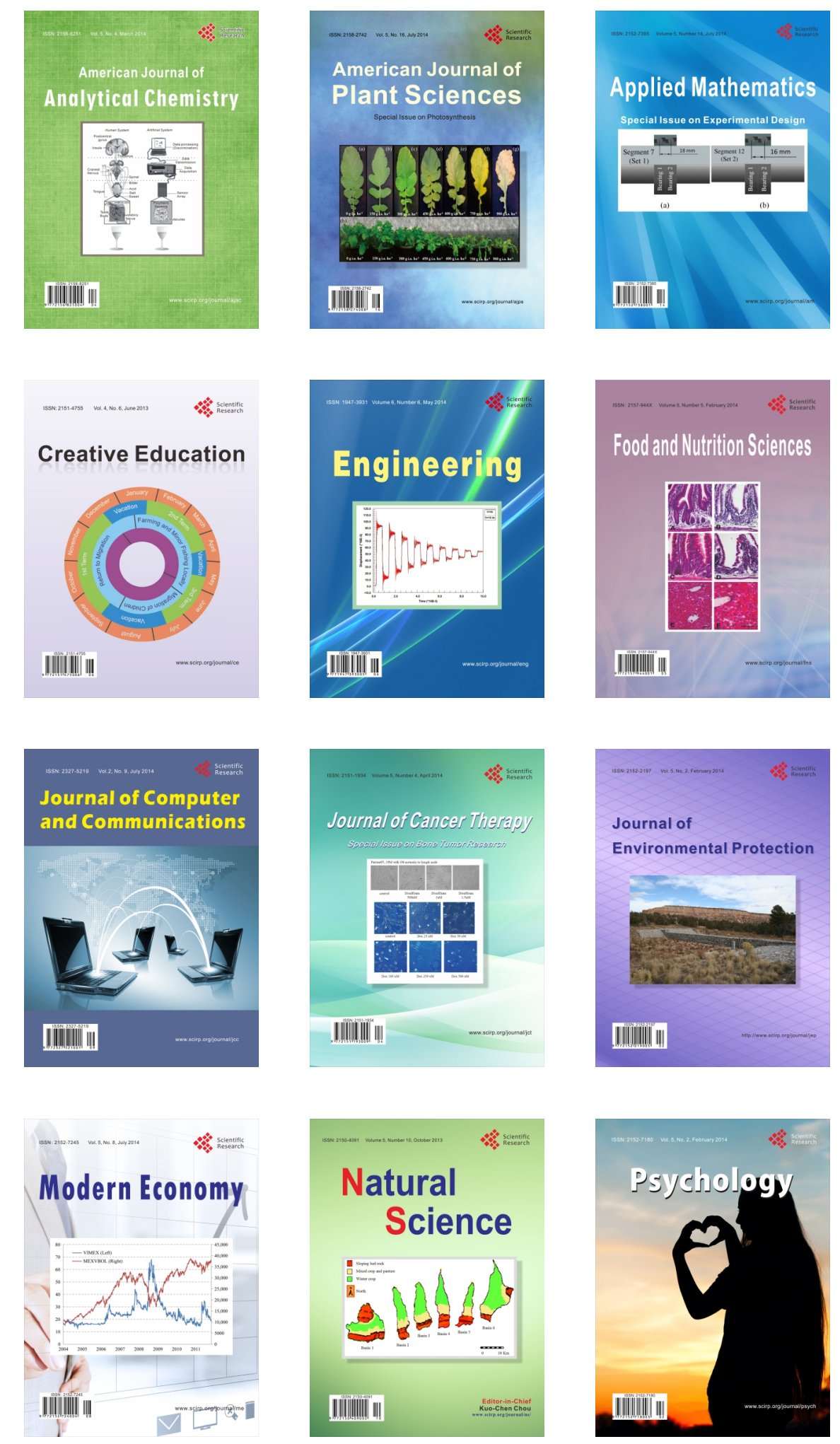